\title{
Ultrasound-Assisted Synthesis and Crystal Structure of Novel 2D Cd (II) Metal-Organic Coordination Polymer with Nitrite End Stop Ligand as a Precursor for Preparation of CdO Nanoparticles
}

\author{
Younes Hanifehpour ${ }^{1, * \mathbb{D}}$, Jaber Dadashi ${ }^{2}$ and Babak Mirtamizdoust ${ }^{2}$ \\ 1 Department of Chemistry, Sayyed Jamaleddin Asadabadi University, Asadabad 6541861841, Iran \\ 2 Department of Chemistry, Faculty of Science, University of Qom, P.O. Box 37185-359, Qom, Iran; \\ jabber_dadashi_95@yahoo.com (J.D.); babakm.tamizdoust@gmail.com (B.M.) \\ * Correspondence: younes.hanifehpour@gmail.com or Hanifehpour@sjau.ac.ir
}

check for updates

Citation: Hanifehpour, Y.; Dadashi, J.; Mirtamizdoust, B.

Ultrasound-Assisted Synthesis and Crystal Structure of Novel 2D Cd (II) Metal-Organic Coordination Polymer with Nitrite End Stop Ligand as a Precursor for Preparation of $\mathrm{CdO}$ Nanoparticles. Crystals 2021, 11, 197. https://doi.org/10.3390/cryst11020197

Academic Editor:

F. Christopher Pigge

Received: 23 December 2020

Accepted: 12 February 2021

Published: 17 February 2021

Publisher's Note: MDPI stays neutral with regard to jurisdictional claims in published maps and institutional affiliations.

Copyright: (C) 2021 by the authors. Licensee MDPI, Basel, Switzerland. This article is an open access article distributed under the terms and conditions of the Creative Commons Attribution (CC BY) license (https:/ / creativecommons.org/licenses/by/ $4.0 /)$.

\begin{abstract}
In the present research, a sonochemical approach was applied to prepare new cadmium(II) coordination $2 \mathrm{D}$ polymer, $\left[\mathrm{Cd}(\mathrm{L})\left(\mathrm{NO}_{2}\right)_{2}\right]_{\mathrm{n}}(\mathrm{L}=1$,2-bis(1-(pyridin-3-yl)ethylidene)hydrazine) and structurally characterized with various spectroscopic techniques including XRD, elemental analysis, SEM, and IR spectroscopy. The coordination number of cadmium (II) ions is seven $\left(\mathrm{CdN}_{2} \mathrm{O}_{5}\right)$ by two nitrogen atoms from two organic Schiff base ligand and five oxygen of nitrite anions. The 2D sheet structures ended by nitrite anions and the nitrite anion displayed the end-stop role. The comprehensive system showed a three-dimensional structure with several weak interactions. The high-intensity ultrasound is regarded as an easy, environmentally-friendly, and flexible synthetic instrument for the compounds of coordination. CdO NPs was obtained by thermolysing 1 at $180{ }^{\circ} \mathrm{C}$ with oleic acid (as a surfactant). Further, the size and morphology of the produced CdO nanoparticles were investigated through SEM.
\end{abstract}

Keywords: crystal structure; coordination polymer; sonochemical route; X-ray crystallography

\section{Introduction}

Recently, the development of metal-organic coordination systems has become increasingly attractive for researchers [1-3]. Ascetic architecture, luminescence, topologic diversity, magnetic, storage molecular, adsorption, covering, various preparation manners, and other interesting possible usage are among the factors attracting attention and results in various examinations leading to many research works in the area of coordination polymers and novel group of material chemistry [4-6].

Schiff bases that are a significant series of organic ligands have the capability of coordination by metal ions for forming stable chelates through the $\mathrm{N}$ atom of the azo-group as well as other donors, like $-\mathrm{NH}_{2}$ and $-\mathrm{OH}$. Schiff bases have advantages of satisfactory biological activity, simple synthetic pathways, high coordination potency, and photochemical features, and they include pharmaceuticals (e.g., antibiotics, anti-inflammatory drugs, and antivirals) and also photoelectric and dye materials [7-12]. Moreover, because of the variety of structure, potential features, and preparative accessibility, metal complexes with Schiff base ligands are considered a significant stereochemical model in metal coordination chemistry. The common coordination mode of these ligands is different and very interesting [13]. Because of the relatively simple yet robust synthetic procedure, Schiff base formation and complexation have formed the basis of a number of elegant reported undergraduate experiments that explore various aspects of Schiff base chemistry, from the formation of organometallic complexes to combinatorial synthesis to spectral analysis. In this experiment, Schiff base ligands are used to demonstrate the effect of metal ions on metal-ligand stoichiometry [14]. 
Metal-organic coordination systems can be used as templates in order to obtain the desired nano-materials. Via selecting proper metal-organic compounds precursors with special morphologies and under suitable experimental conditions, acquiring the desired morphologies will become possible. Nano metal-organic coordination compounds precursors may also be used to obtain nano-materials with better and more useful properties [15-18]. Depending on the conditions, metal-organic coordination compounds precursor may lead to the preparation of metals, metal oxides, metal sulfides, or other nano-sized materials. With this method, nano-materials can be obtained in different morphologies from different metal-organic coordination systems precursors.

A small number of the transition metals' characteristic attributes are demonstrated by Cadmium and group 12 elements because they do not partially fill $\mathrm{d}$ or $\mathrm{f}$ electron shells. Cadmium, like zinc, has a preference for a +2 oxidation state in the majority of its complexes. However, the more important point is that these elements with spherical $\mathrm{d}^{10}$ configuration are the facilitators of different coordination geometries, allowing forming of 1D, 2D, and 3D coordination compounds [19-21].

The focus of the present study is the preparation and design of metal-organic coordination systems, and the synthesis of some nano metal-organic coordination polymers have been recently reported by our research team [22-26]. The next phase of our team in this regard is an investigation of the behaviors of Cadmium (II) in terms of coordination by 2-bis(1-(pyridin-3-yl)ethylidene)hydrazine) Schiff-base ligand in the present work.

The near similar works on these compounds were reported in previous literature with various composite and applicant (see [27]). Especially, the ligand's structural chemistry is attractive due to its multifunctional coordination state which four aromatic and aliphatic nitrogen can be coordinated to metals (Scheme 1). A simple sonochemical preparation process is described in this work for a nanostructure for this coordination system and its usage in the construction of Cadmium oxide (CdO) NPs.

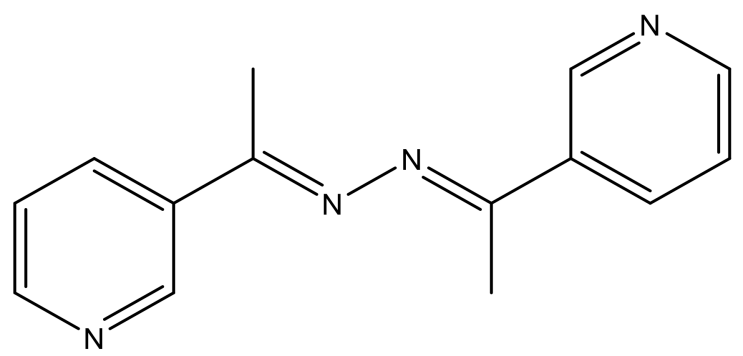

Scheme 1. Schematic of 2-bis (1-(pyridin-3-yl)ethylidene)hydrazine) Schiff-base ligand.

\section{Experimental}

\subsection{Instruments and Materials}

All chemical compounds were bought from the Aldrich and Merck (Germany and Merck Company, Darmstadt, Germany) chemical companies. A Bruker Vector 22 FTIR (Richmond Scientific, Chorley, UK) spectrometer with KBr disks in the area of 400$4000 \mathrm{~cm}^{-1}$ was used for acquiring IR spectroscopy. An Electrothermal 9000 (Keison Products, Chelmsford, UK) apparatus determine the melting points. A multiwave ultrasonic generator (Sonicator_3000; Misonix, Inc., Farmingdale, NY, USA) was applied. X'pert diffractometer (produced by Panalytical, Panalytical, Malvern, UK) monochromatized $\mathrm{Cu}$ $\mathrm{K}_{\alpha}$ radiation was employed for performing measurements of PXRD. Mercury 2.4 was used for preparing simulated PXRD powder patterns on the basis of single-crystal data [28]. Elemental analyses were carried out using a linked ISIS-300, Oxford EDS (Oxford Instruments, Abingdon, UK) (energy dispersion spectroscopy) detector. Chemical states and chemical compositions of the $\mathrm{CdO}$ nanoparticles were carried out through X-ray photoelectron spectroscopy (XPS) (Model: K-ALPHA, Thermo Fisher, Waltham, MA, USA).

The Scherrer formula was employed for estimating the crystallite size of chosen samples. Followed by gold coating Au, the samples' morphology was assessed using an 
SEM (Hitachi, Japan). Using an XcaliburTM diffractometer with a Sapphire2 CCD detector and Mo K $\alpha$ radiation (monochromator Enhance, Oxford Diffraction Ltd., Abingdon, UK) and $\omega$-scan rotation methods at $150 \mathrm{~K}$, diffraction data were collected for the single crystal. The CrysAlis program package (Oxford Diffraction Ltd., UK) was utilized for data reduction and gathering and refinement of cell parameters [29].

Multi-scan absorption modification with the CrysAlis (Rigaku, Tokyo, Japan) was used for the $[\mathrm{Cd}(\mathrm{L})(\mathrm{NO} 2) 2] \mathrm{n}$ data. With a full matrix weighted least-squares method (SHELX2014) (Free Software Foundation, Boston, MA, US) with the $\mathrm{w}=1 /\left[\sigma^{2}\left(\mathrm{~F}_{\mathrm{o}}\right)^{2}+(0.035 \mathrm{P})^{2}\right]$ weight, where $\mathrm{P}=\left(\mathrm{F}_{\mathrm{o}}{ }^{2}+2 \mathrm{~F}_{\mathrm{c}}{ }^{2}\right) / 3$, we solved the structure with direct processes by SHELXS and adjusted on all $\mathrm{F}^{2}$ data anisotropically. Mercury 2.4 was applied for creating molecular exhibits. Crystal data and arrangement modification for 1 are provided in Table 1, and the designated bond lengths and angles can be observed in Table 2 .

Table 1. Crystal data and structure refinements of complex.

\begin{tabular}{|c|c|}
\hline Chemical Formula & $\mathrm{C}_{14} \mathrm{H}_{14} \mathrm{CdN}_{6} \mathrm{O}_{4}$ \\
\hline $\mathrm{M}_{\mathrm{r}}$ & 442.7 \\
\hline Crystal system, space group & Orthorhombic, $P 2{ }_{1} 2_{1} 2_{1}$ \\
\hline Temperature $(\mathrm{K})$ & 120 \\
\hline$a, b, c(\AA)$ & $4.5208(1), 16.2510(2), 22.0539(4)$ \\
\hline$V\left(\AA^{3}\right)$ & $1620.25(5)$ \\
\hline $\mathrm{Z}$ & 4 \\
\hline Radiation type & $\mathrm{Cu} K \alpha$ \\
\hline$\mu\left(\mathrm{mm}^{-1}\right)$ & 11.12 \\
\hline Crystal size (mm) & $0.38 \times 0.10 \times 0.03$ \\
\hline Diffractometer & Goniometer Xcalibur, detector: Atlas (Gemini ultra Cu) \\
\hline Absorption correction & $\begin{array}{l}\text { Analytical CrysAlis PRO, Agilent Technologies (2010), Analytical } \\
\text { numeric absorption correction using a multifaceted crystal model }\end{array}$ \\
\hline $\mathrm{T}_{\min }, \mathrm{T}_{\max }$ & $0.181,0.723$ \\
\hline $\begin{array}{l}\text { No. of measured, idenpendent and observes } \\
\qquad[1>2 \sigma(1) \text { reflections }\end{array}$ & $20706,2895,2742$ \\
\hline$R_{\text {int }}$ & 0.039 \\
\hline$(\sin \theta / \lambda)_{\max }\left(\AA^{-1}\right)$ & 0.598 \\
\hline Refinement $\mathrm{R}\left[\mathrm{F}^{2}>2 \sigma\left(\mathrm{F}^{2}\right)\right], w \mathrm{R}\left(\mathrm{F}^{2}\right), \mathrm{S}$ & $0.020,0.057,1.13$ \\
\hline No. of reflections & 2895 \\
\hline No. of parameters & 227 \\
\hline H-atom treatment & $\mathrm{H}$-atom parameters constrained \\
\hline$\Delta>_{\max }, \Delta>_{\min }\left(\mathrm{e} \AA^{-3}\right)$ & $0.30,-0.37$ \\
\hline
\end{tabular}

Table 2. Chosen bond lengths $[\AA ̊]$ \& angles $\left[{ }^{\circ}\right]$ for 1 .

\begin{tabular}{cccc}
\hline $\mathbf{1 . 2 3 4}(\mathbf{4})$ & O2-N5 & $\mathbf{2 . 3 9 0 ( 2 )}$ & Cd1-O1 \\
\hline $1.252(5)$ & $\mathrm{O} 3-\mathrm{N} 6$ & $2.368(2)$ & $\mathrm{Cd} 1-\mathrm{O} 3$ \\
$1.255(5)$ & $\mathrm{O} 4-\mathrm{N} 6$ & $2.470(2)$ & $\mathrm{Cd} 1-\mathrm{O} 2$ \\
$1.335(5)$ & $\mathrm{N} 1-\mathrm{C} 1$ & $2.389(2)$ & $\mathrm{Cd} 1-\mathrm{O} 4$ \\
$1.340(5)$ & $\mathrm{N} 1-\mathrm{C} 5$ & $2.328(2)$ & $\mathrm{Cd} 1-\mathrm{O} 1^{\mathrm{i}}$ \\
$1.397(5)$ & $\mathrm{N} 2-\mathrm{N} 3$ & $2.358(2)$ & $\mathrm{Cd} 1-\mathrm{N} 1^{\mathrm{i}}$ \\
$1.291(5)$ & $\mathrm{N} 2-\mathrm{C} 6$ & $2.356(2)$ & $\mathrm{Cd} 1-\mathrm{N} 4$ \\
$1.346(5)$ & $\mathrm{N} 4-\mathrm{C} 12$ & $1.288(5)$ & $\mathrm{N} 3-\mathrm{C} 8$ \\
$120.2(2)$ & $\mathrm{Cd} 1 \mathrm{ii}-\mathrm{N} 1-\mathrm{C} 5$ & $1.339(5)$ & $\mathrm{N} 4-\mathrm{C} 11$ \\
$154.44(9)$ & $\mathrm{N} 11^{\mathrm{i}}-\mathrm{Cd} 1-\mathrm{N} 4$ & $87.27(11)$ & $\mathrm{O} 1-\mathrm{Cd} 1-\mathrm{N} 1^{\mathrm{i}}$ \\
$121.9(2)$ & $\mathrm{Cd} 1 \mathrm{ii}-\mathrm{N} 1-\mathrm{C} 1$ & $89.09(10)$ & $\mathrm{Od} 1-\mathrm{N} 4$ \\
\hline
\end{tabular}

Symmetry code(s): (i) $-x, y+1 / 2,-z+1 / 2$; (ii) $-x, y-1 / 2,-z+1 / 2$.

\subsection{Preparation of 1,2-Bis(1-(pyridin-3-yl)ethylidene)hydrazine) Ligand}

$20 \mathrm{mmol}$ (1.9 mL, $2.42 \mathrm{~g})$ of 1-(pyridin-3-yl)ethan-1-one was dissolved in $50 \mathrm{~mL}$ of ethanol, then $10 \mathrm{mmol}(0.9 \mathrm{~mL}, 0.91 \mathrm{~g})$ of hydrazine hydrate (35 wt \% solution in water), softened in $20 \mathrm{~mL}$ of ethanol, was mixed in a drop-wise manner; subsequently, two acetic 
acid drops were mixed with it too. The stirring of the reaction mix was done for $24 \mathrm{~h}$ at ambient temperature. Finally, the yellow sediments were filtered and air-dried (yield: 77\%, $2.56 \mathrm{~g}$ product) (Comparable with previous synthesized [30,31]). 1600(s).

FT-IR (KBr, cm $\left.{ }^{-1}\right)$ : 758(m), 823(w), 563(m), 1290(s), 1365(s), 1415(s), 1485(s), 1558(s),

Elemental analysis calculated for $\mathrm{C}_{14} \mathrm{H}_{14} \mathrm{~N}_{4}$ : C: $70.57, \mathrm{H}: 5.92, \mathrm{~N}: 23.51 \%$.

Experimental: C: $70.10, \mathrm{H}: 6.00, \mathrm{~N}: 24.00 \%$.

\subsection{Synthesis of Nano-Structure of $\left[\mathrm{Cd}(\mathrm{L})\left(\mathrm{NO}_{2}\right)_{2}\right]_{n}$}

For synthesizing, the nanostructure of $\left[\mathrm{Cd}(\mathrm{L})\left(\mathrm{NO}_{2}\right)_{2}\right]_{\mathrm{n}}$ a solution of cadmium(II) nitrate tetrahydrate $(15 \mathrm{~mL}$ of a $0.1 \mathrm{M})$ in water was put in a high-density ultrasonic probe operating at $20 \mathrm{kHz}$ by the highest power output of $60 \mathrm{~W}$. $15 \mathrm{~mL}$ of a $0.1 \mathrm{M}$ solution of the Schiff base ligand and $30 \mathrm{~mL}$ of a $0.1 \mathrm{M}$ solution of sodium nitrite were added into this solution in a drop-wise manner. The resulting yellow precipitates were filtered, rinsed with $\mathrm{H}_{2} \mathrm{O}$ and $\mathrm{MeOH}$, and dried at $50{ }^{\circ} \mathrm{C}\left(0.69 \mathrm{~g}\right.$ product/yield: $65 \%$ decompose point: $\left.210{ }^{\circ} \mathrm{C}\right)$

Elemental analysis; calculated for $\mathrm{C}_{14} \mathrm{H}_{14} \mathrm{CdN}_{6} \mathrm{O}_{4}: \mathrm{C}: 37.98, \mathrm{H}: 3.19, \mathrm{~N}: 18.98 \%$.

Experimental: C: $38.00, \mathrm{H}: 4.10, \mathrm{~N}: 20.00$.

\subsection{Synthesis of Isolate Single Crystal of $\left[\mathrm{Cd}(\mathrm{L})\left(\mathrm{NO}_{2}\right)_{2}\right]_{n}$}

For isolating $\left[\mathrm{Cd}(\mathrm{L})\left(\mathrm{NO}_{2}\right)_{2}\right]_{\mathrm{n}}$ single crystals, Schiff base ligand $(1 \mathrm{mmol} / 0.24 \mathrm{~g})$, sodium nitrite $(2 \mathrm{mmol} / 0.14 \mathrm{~g})$ and cadmium(II) nitrate tetrahydrate $(1 \mathrm{mmol} / 0.31 \mathrm{~g})$ were put in the primary arm of a branched tube for heating (Scheme 2) [32].

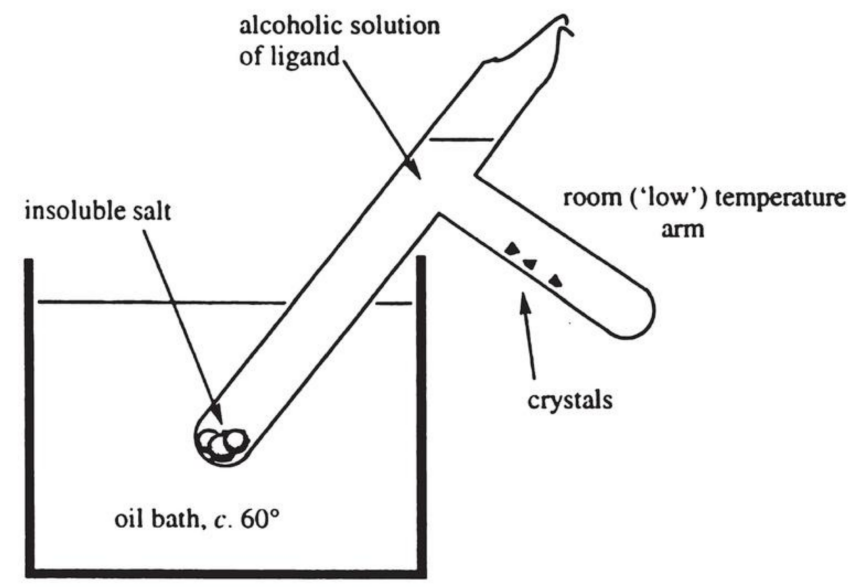

Scheme 2. Brached tube method [32].

Both arms received methanol carefully. The tube was sealed, and the arm containing ligand was submerged in an oil bath at $60^{\circ} \mathrm{C}$; however, the other arm was stored at ambient temperature. Following two weeks, yellow crystals were precipitated in the colder arm for X-ray structure determination that was filtered, rinsed by acetone and ether, and being dried with exposure to air. (0.59 g product/Yield $89 \%$-decompose point: $\left.210{ }^{\circ} \mathrm{C}\right)$ Elemental analysis; calculated for C14H14CdN6O4: C: 37.98, H: 3.19, N: 18.98\%. Experimental: C: 38.00, H: 4.00, N: 20.00

\section{Synthesis of CdO Nanoparticles}

The precursor of $[\mathrm{Cd}(\mathrm{L})(\mathrm{NO} 2) 2] \mathrm{n}(\mathbf{1})(0.02 \mathrm{mmol})$ was dissolved instantly in $1.0 \mathrm{~mL}$ of oleic acid, which formed a light yellow solution. This solution was degassed for $20 \mathrm{~min}$ and then heated to $180^{\circ} \mathrm{C}$ for $2 \mathrm{~h}$. At the end of the reaction, an orange precipitate was formed. A small amount of toluene and a large excess of $\mathrm{EtOH}$ were added to the reaction solution, and cadmium (II) oxide nanoparticles were separated by centrifugation. The light brown solids were washed with $\mathrm{EtOH}$ and dried under an air atmosphere ( $0.01 \mathrm{~g}$ product/yield: $58 \%)$. 


\section{Results and Discussion}

The reaction of 1,2-bis(1-(pyridin-3-yl)ethylidene)hydrazine) Schiff base ligand with a mixture of sodium nitrite and cadmium nitrate, the novel Cd (II) metal-organic coordination polymer $\left[\mathrm{Cd}(\mathrm{L})\left(\mathrm{NO}_{2}\right)_{2}\right]_{\mathrm{n}}$ was obtained. Using ultrasonic irradiation in a methanolic solution, the compound's nanostructure was achieved; then, the single crystalline substance was attained through application of the heat gradients to the reagents solution or branched tube route. Scheme 3 presents the two various routes utilized for preparing $\left[\mathrm{Cd}(\mathrm{L})\left(\mathrm{NO}_{2}\right)_{2}\right]_{\mathrm{n}}$ materials.

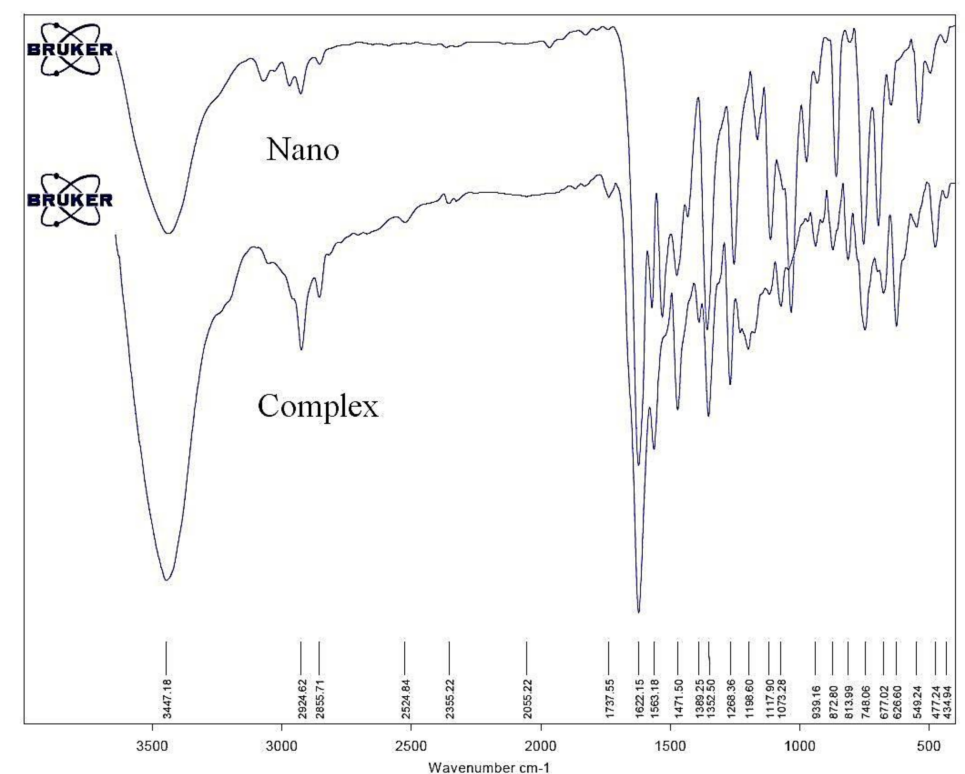

Figure 1. FT-IR spectra of the complex and nano-structures of coordination polymer.

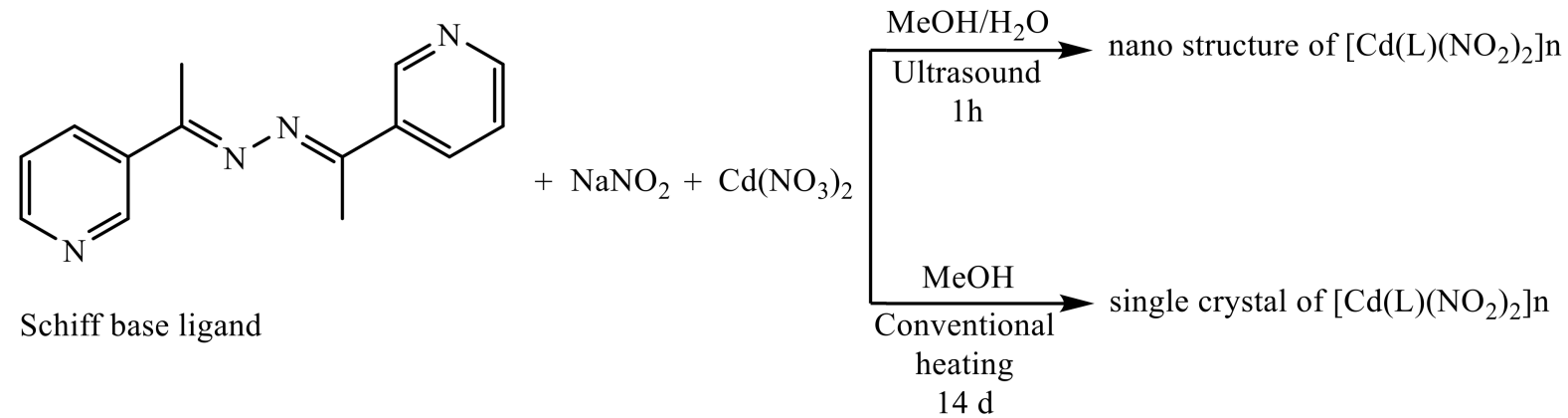

Scheme 3. The synthetic techniques and the produced materials. The FT-IR spectra of synthesized crystal and nano-structure of coordination polymer $\left(\left[\mathrm{Cd}(\mathrm{L})\left(\mathrm{NO}_{2}\right)_{2}\right]_{\mathrm{n}}\right)$ indicate the characteristic absorption bands for organic Schiff base ligand. The weak band near $3000-3100 \mathrm{~cm}^{-1}$ is assigned to aromatic $\mathrm{C}-\mathrm{H}$ groups' stretching vibrations. The $\mathrm{C}=\mathrm{N}$ tensile band is a sharp and strong peak in the 1622 area. The absorption band in the $1400-1600 \mathrm{~cm}^{-1}$ range is attributed to the Schiff base ligand's aromatic ring vibrations. There is a good match between FT-IR spectra of the complex and nano-structure in all areas (Figure 1).

The surface morphology of the synthesized nano coordination compound was investigated through FE-SEM (field emission scanning microscopy) analysis. The morphology of the compound prepared by the sonochemical method is block-like aggregates (Figure 2). SEM assessments illustrate that achieved nanoparticles are of various sizes and have different shapes. Figure 3 showed the Simulated XPRD pattern of $\left[\mathrm{Cd}(\mathrm{L})\left(\mathrm{NO}_{2}\right)_{2}\right]_{\mathrm{n}}$ in comparison with nanostructure XRD pattern, Acceptable matches with slight differences in $2 \theta$ were observed between the simulated and experimental XPRD patterns (Figure 3). This indicates that the synthesis obtained by the sonochemical method as nanoparticles is identical to 
that obtained by crystallography. The significant broadening of the peaks indicates that the particles are of nanometer dimensions. As it has been estimated by the Sherrer formula $(D=0.891 \lambda / \beta \cos \cdot \theta$, where $D$ is the average grain size, $\lambda$ the $X$-ray wavelength $(0.15405 \mathrm{~nm})$, and $\theta$ and $\beta$ the diffraction angle and full-width at half maximum of an observed peak, respectively) [33], the obtained value is $D=83 \mathrm{~nm}$.

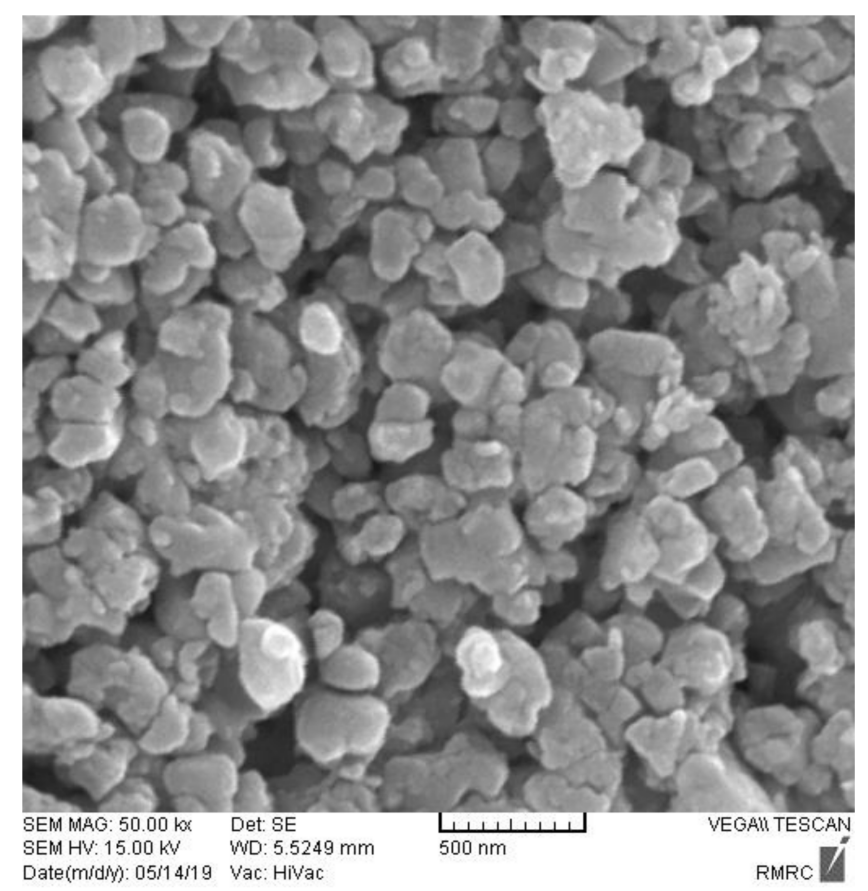

Figure 2. SEM images of the $\left[\mathrm{Cd}(\mathrm{L})\left(\mathrm{NO}_{2}\right)_{2}\right]_{\mathrm{n}}$.

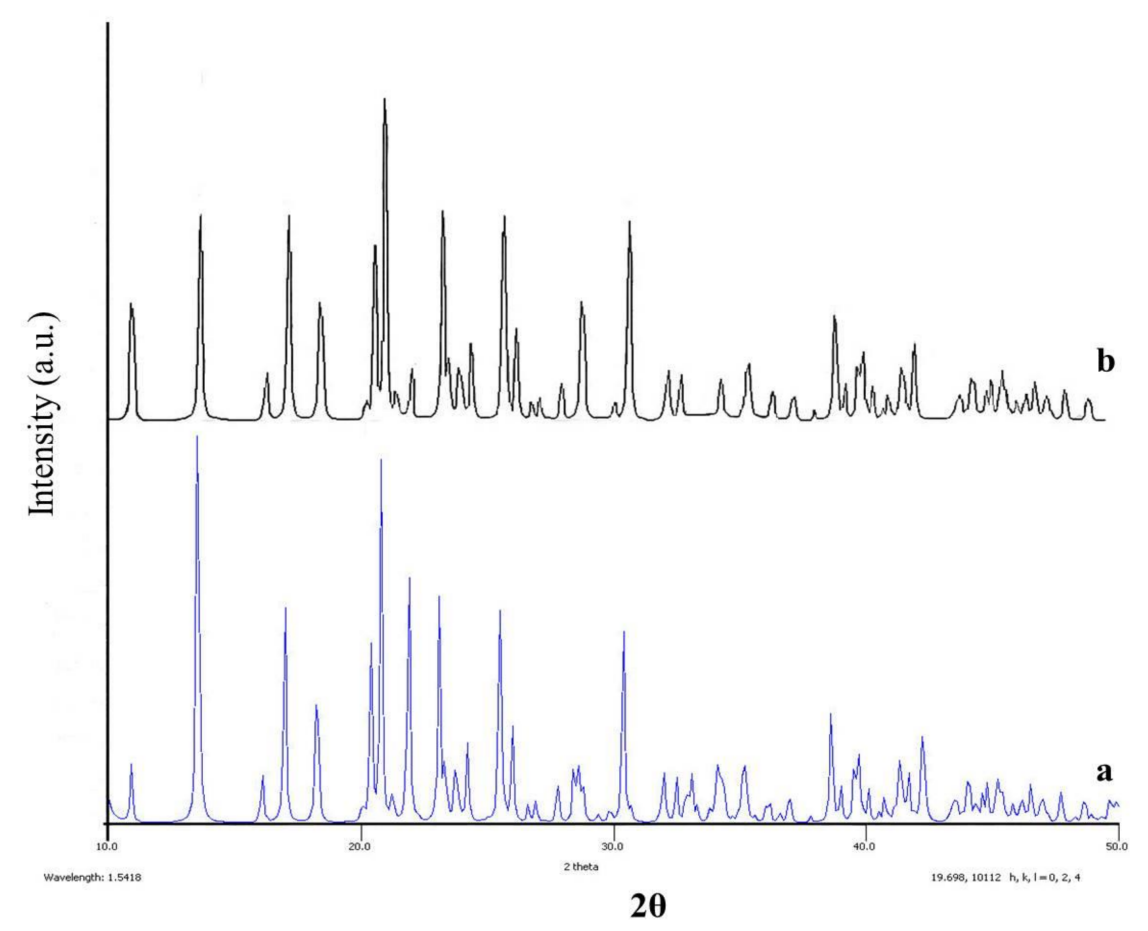

Figure 3. The PXRD patterns of compound $\left[\mathrm{Cd}(\mathrm{L})\left(\mathrm{NO}_{2}\right)_{2}\right]_{\mathrm{n}}(\mathbf{1})$ : (a) Simulated from single-crystal Xray data and (b) nanostructure of (1) prepared by sonochemical method. Based on the crystal structure of $\mathbf{1}$, the composition and stereochemistry of a building block $\left.\left[\mathrm{Cd}(\mathrm{L})\left(\mathrm{NO}_{2}\right)_{2}\right]_{\mathrm{n}}\right)$ were disclosed. A view of the molecular structure is shown in Figure 4. 


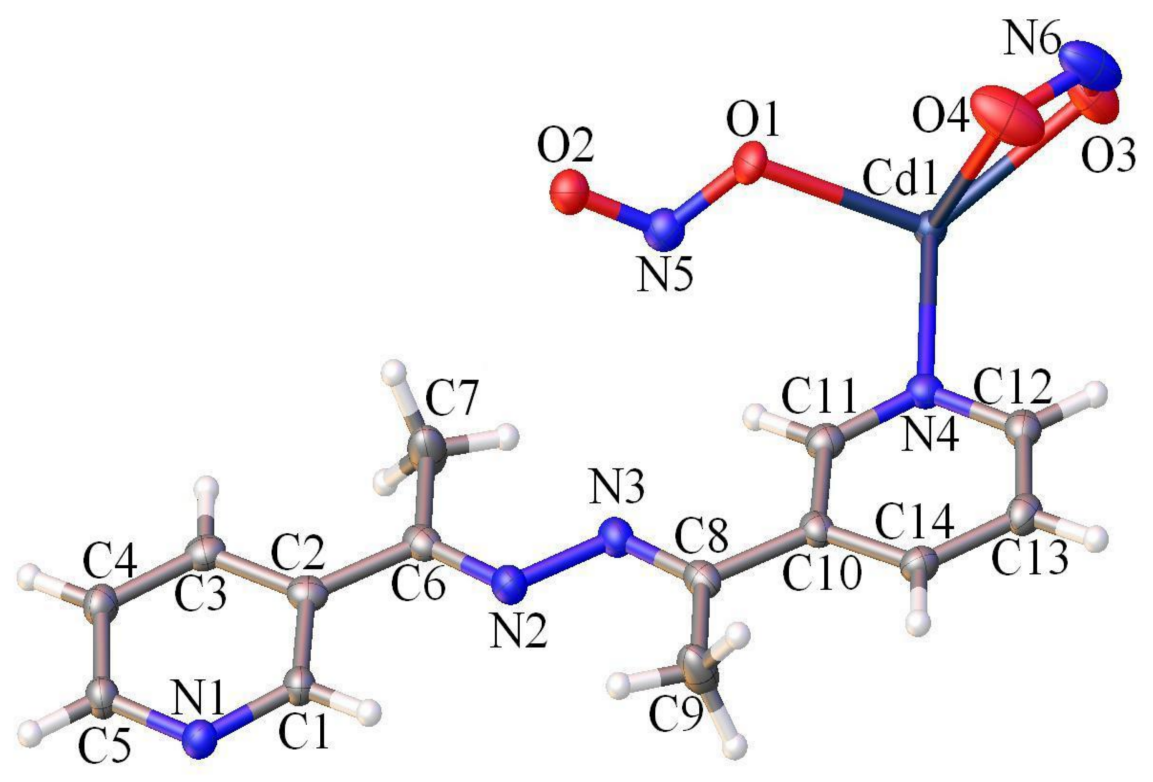

Figure 4. Asymmetric unit of the $\left[\mathrm{Cd}(\mathrm{L})\left(\mathrm{NO}_{2}\right)_{2}\right]_{\mathrm{n}}$.

The determination of the structure of coordination polymer $\left[\mathrm{Cd}(\mathrm{L})\left(\mathrm{NO}_{2}\right)_{2}\right]_{\mathrm{n}}$ displayed that the complex crystallizes in the Orthorhombic system with space group $P 2_{1} 2_{1} 2_{1}$, taking the form of a two-dimensional polymer in the solid-state (Figure 5). The Cd (II) atom is coordinated with two nitrogen atoms of two Schiff base ligands with the $\mathrm{Cd}-\mathrm{N}$ distances of 2.356 (2), 2.358 (2) $\AA$, five oxygen atoms of three nitrite anions. In addition distance of $\mathrm{Cd}-\mathrm{O}$ bonds in this complex are around 2.368-2.247 $\AA$. Therefore, the coordination number of the Cd (II) atom is seven, with an orthorhombic system with space group $P 2{ }_{1} 2_{1} 2_{1}$ (Figures 4 and 5) (See Appendix A for further details). The 2D sheet structures ended with nitrite anions. In this structure, the nitrite anion showed the end-stop role and by connecting directly to the metal, does not allow the system to expand to the third dimension.

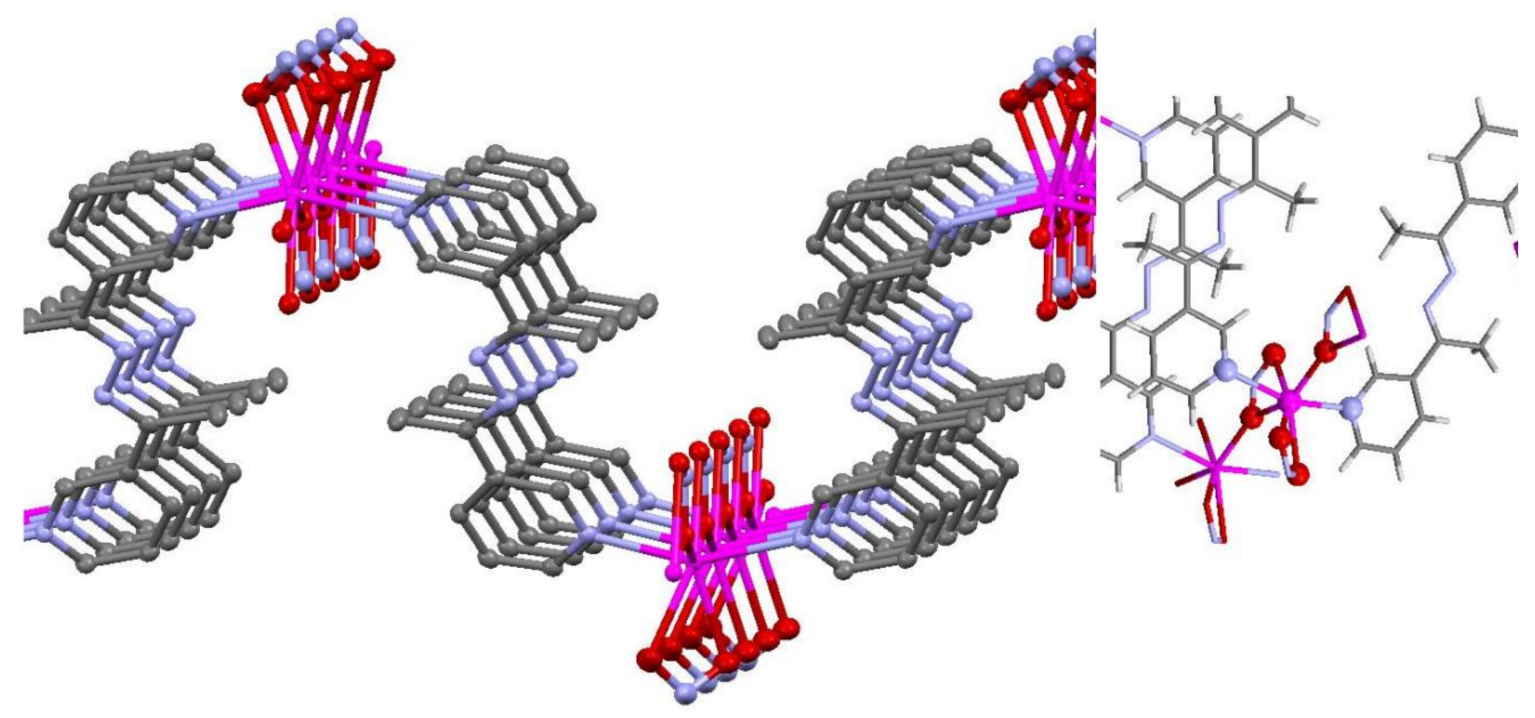

Figure 5. The coordination polymer fragment showing the 2D arrangement of complex (Left), The coordination sphere of Cd(II) (Right).

The structure of other compounds reported from this ligand to $\mathrm{Mn}, \mathrm{Ag}, \mathrm{Co}, \mathrm{Zn}, \mathrm{Bi}$, and $\mathrm{Hg}$ metals with varying coordination numbers for metals and the same coordination method for ligands is comparable [34-38]. 
There are many weak interactions exist in the structure; (like short contact involving $\mathrm{C}-\mathrm{H}$ groups and aromatic interactions) (See Table 3. For example, there are pi-pi stacking interactions between the N1C5C4C3C3C1 plans about $3.770 \AA$ and between the N4C12C13C14C10C11 plans about 3.474 A. With several weak interactions, the 2D chains interact with neighbors, and the system extended to 3-dimensional structures (Figure 6 and Table 3).

Table 3. Selected non-covalent contacts in the crystal structure of $\mathbf{1}\left[\AA\right.$ and $\left.^{\circ}\right]$.

\begin{tabular}{ccccc}
\hline D-H...A & d(D-H) & d(H...A) & d(D...A) & $<($ DHA) \\
\hline $\mathrm{C}(13)-\mathrm{H}(13) \ldots \mathrm{O}(4)$ & 0.96 & 2.525 & $3.237(4)$ & 130.9 \\
$\mathrm{C}(13)-\mathrm{H}(7) \ldots \mathrm{C}(12)$ & 0.96 & 2.708 & $2.789(4)$ & 155.5 \\
$\mathrm{C}(4)-\mathrm{H}(4) \ldots \mathrm{O}(3)$ & 0.95 & 2.572 & $3.442(5)$ & 151.2 \\
$\mathrm{C}(1)-\mathrm{H}(1) \ldots \mathrm{N}(5)$ & 0.96 & 2.514 & $3.328(4)$ & 142.6 \\
$\mathrm{C}(5)-\mathrm{H}(5) \ldots \mathrm{O}(3)$ & 0.95 & 2.641 & $3.674(5)$ & 145.7 \\
\hline
\end{tabular}
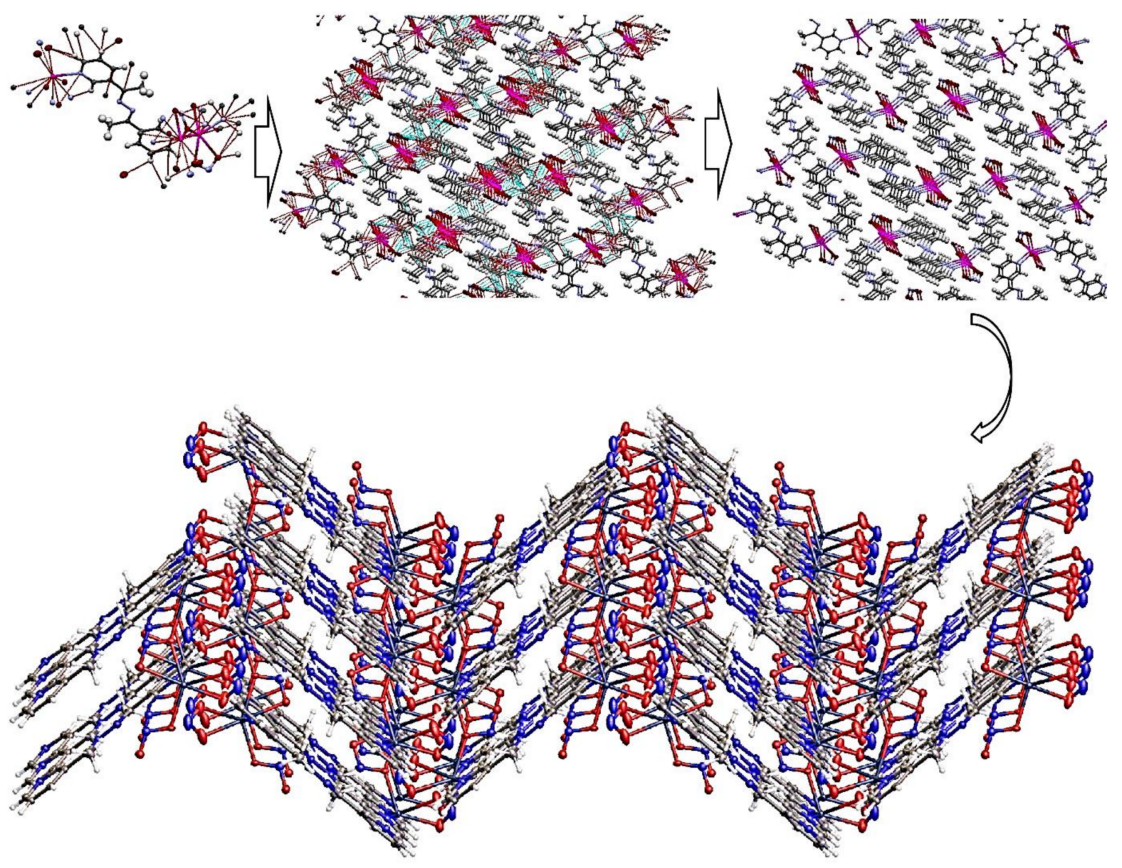

Figure 6. From di nuclear complexes to 3D networks.

The decomposition of precursor $\left[\mathrm{Cd}(\mathrm{L})\left(\mathrm{NO}_{2}\right)_{2}\right]_{\mathrm{n}}$ in oleic acid functioning as a surfactant under an air atmosphere at $180{ }^{\circ} \mathrm{C}$ yields nano-powder of cadmium (II) oxide. The PXRD pattern of as-synthesized CdO nanopowder is seen in Figure 7. All the diffraction peaks are matched well with the cubic crystal structure of pure $\mathrm{CdO}$ with respect to their positions as found in JCPDS card No.05-0640.

Figure 8 displays the energy-dispersive $\mathrm{X}$-ray spectroscopy (EDS) of the $\mathrm{CdO}$ nanoparticles and confirms the existence of the elements $\mathrm{Cd} / \mathrm{O}$ and the formation of $\mathrm{CdO}$ as expected. The atomic percentage composition of the elements $\mathrm{Cd}$ and $\mathrm{O}$ were observed to be equal to 50.79 and 49.21 , respectively.

Figure 9a displays the SEM image of as-prepared CdO nanoparticles. The obtained $\mathrm{CdO}$ has the regular nanoparticle shape with diameters of around $30-80 \mathrm{~nm}$ according to the size distribution graph of the product which was determined using Nahamin microstructure distance measurement software (Iran). (Figure 9b). 


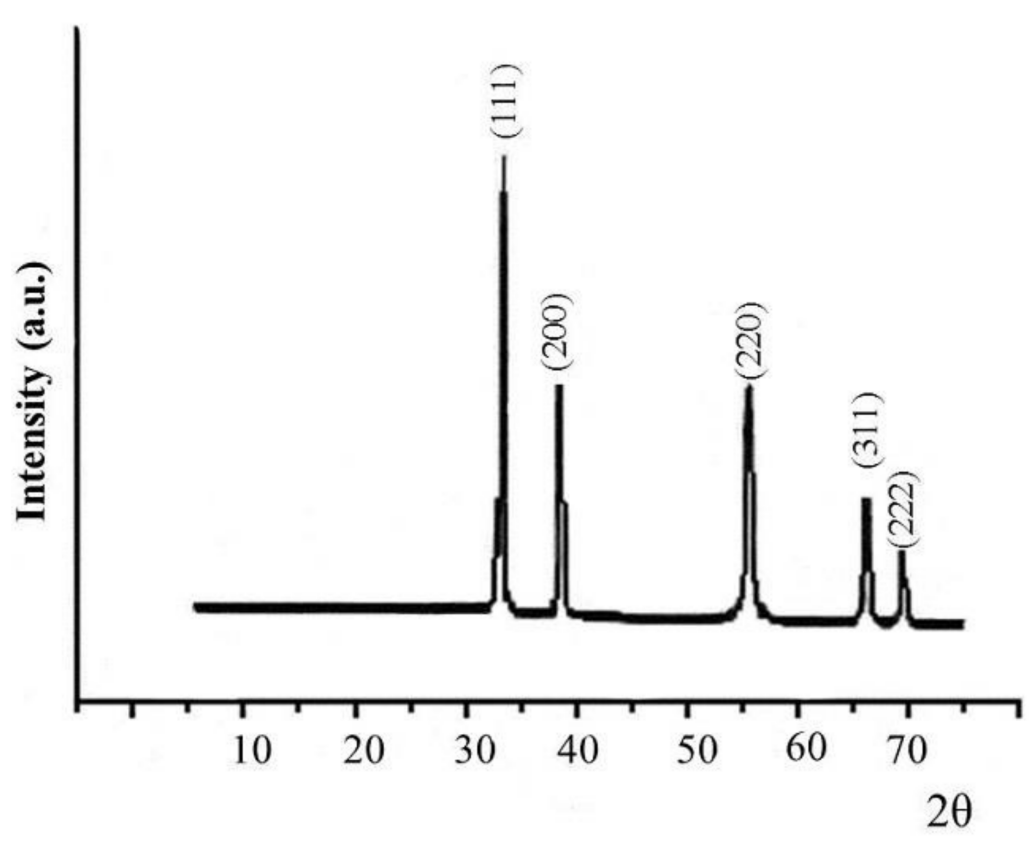

Figure 7. XRD pattern of cadmium oxide obtained by decomposition of (1).

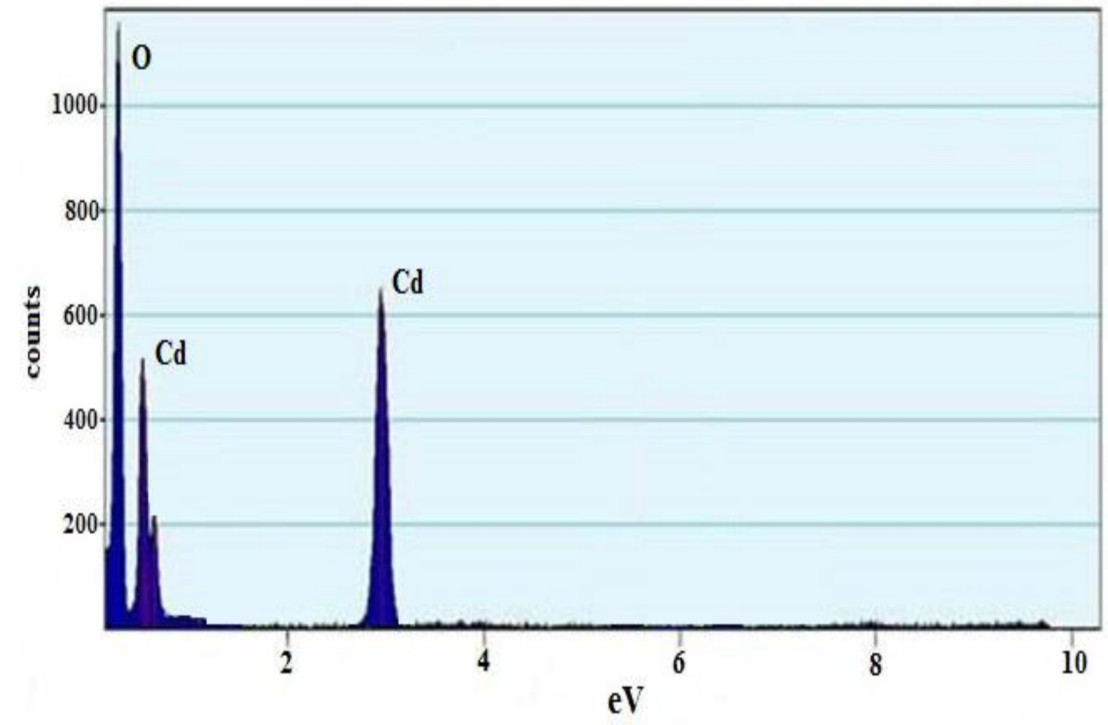

Figure 8. EDX of the as-prepared CdO nanoparticles.
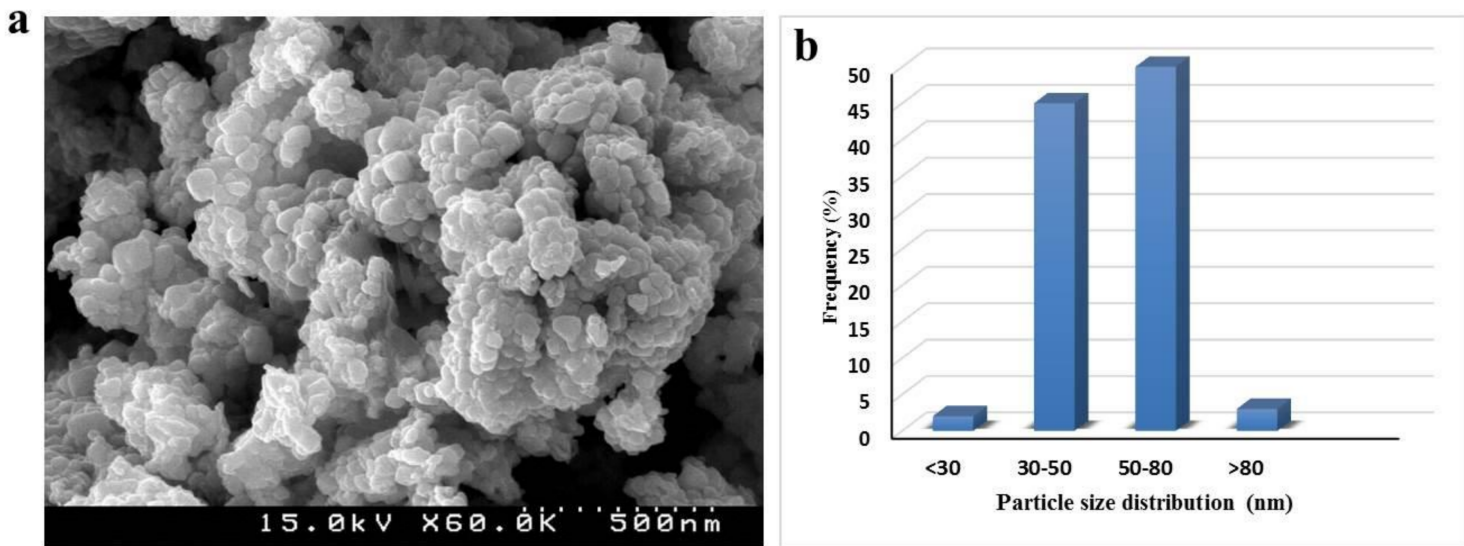

Figure 9. (a) SEM photograph and (b) size distribution graph of nano cadmium oxide (obtained by thermolysis of precursor 1). 
The XPS spectrum (Figure 10) confirms the presence of $\mathrm{O}$ and $\mathrm{Cd}$ in the sample. The binding energy corresponding to the peaks $\mathrm{O} 1 \mathrm{~s}, \mathrm{Cd} 3 \mathrm{~d} 5 / 2$, and $3 \mathrm{~d} 3 / 2$ obtained by XPS analysis is $530.03,405.6$, and $412.9 \mathrm{eV}$, respectively [39].

Cd3d Scan

2 Scans, $40.2 \mathrm{~s}, 400 \mu \mathrm{m}, \mathrm{CAE} 40.0$

$0.10 \mathrm{eV}$

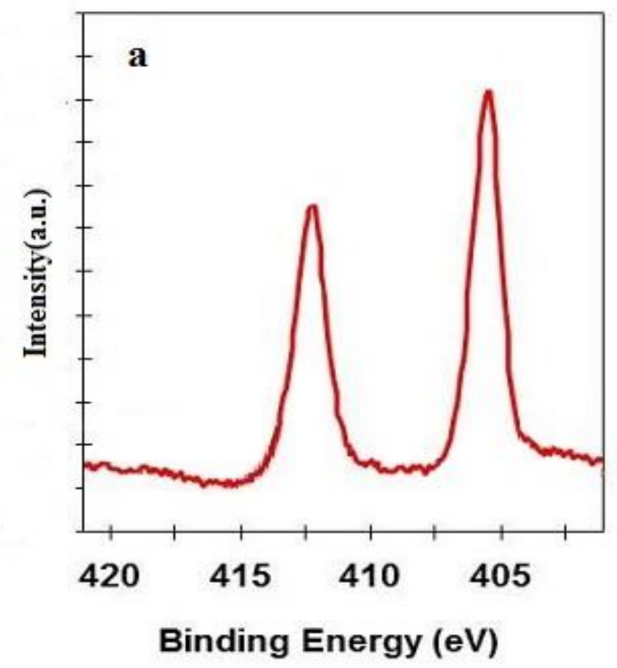

O1s Scan

2 Scans, $40.2 \mathrm{~s}, 400 \mu \mathrm{m}$, CAE 40.0

$0.10 \mathrm{eV}$

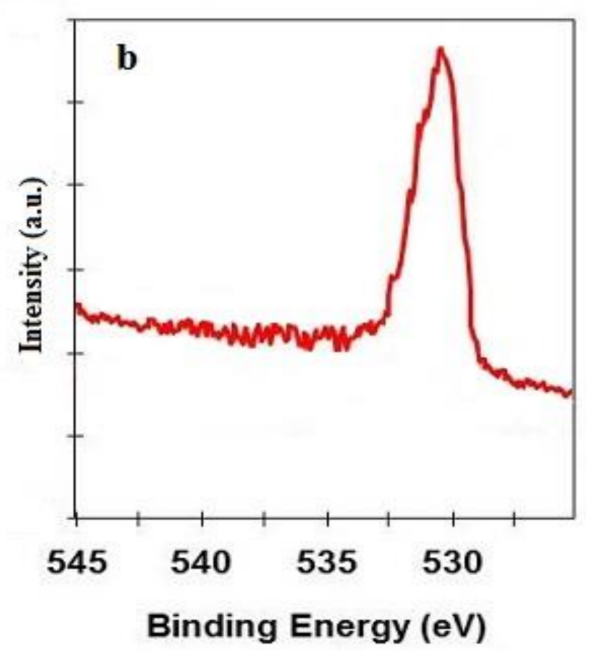

Figure 10. CdO XPS spectra (a) Cd scan and (b) O scan obtained by thermolysis of $\mathbf{1}$.

The thermal gravimetric (TG) analysis was applied to evaluate the thermal stability of the $\left[\mathrm{Cd}(\mathrm{L})\left(\mathrm{NO}_{2}\right)_{2}\right]_{\mathrm{n}} \mathbf{1}$. TG was recorded in the temperature range of 20 and $800{ }^{\circ} \mathrm{C}$. The diagram of 1 depicts that the compound remains stable up to $125^{\circ} \mathrm{C}$, and then decomposes up to $210{ }^{\circ} \mathrm{C}$. The first weight loss is related to the removal of the $\mathrm{NO}_{2}$ unit. The step 2 in the range $300{ }^{\circ} \mathrm{C}$ to $380{ }^{\circ} \mathrm{C}$ with sharp weight loss is attributed to an organic moiety of 1 with a mass loss of about $45.3 \%$. The remained solid around $800{ }^{\circ} \mathrm{C}$ is probably $\mathrm{CdO}$ (Figure 11).

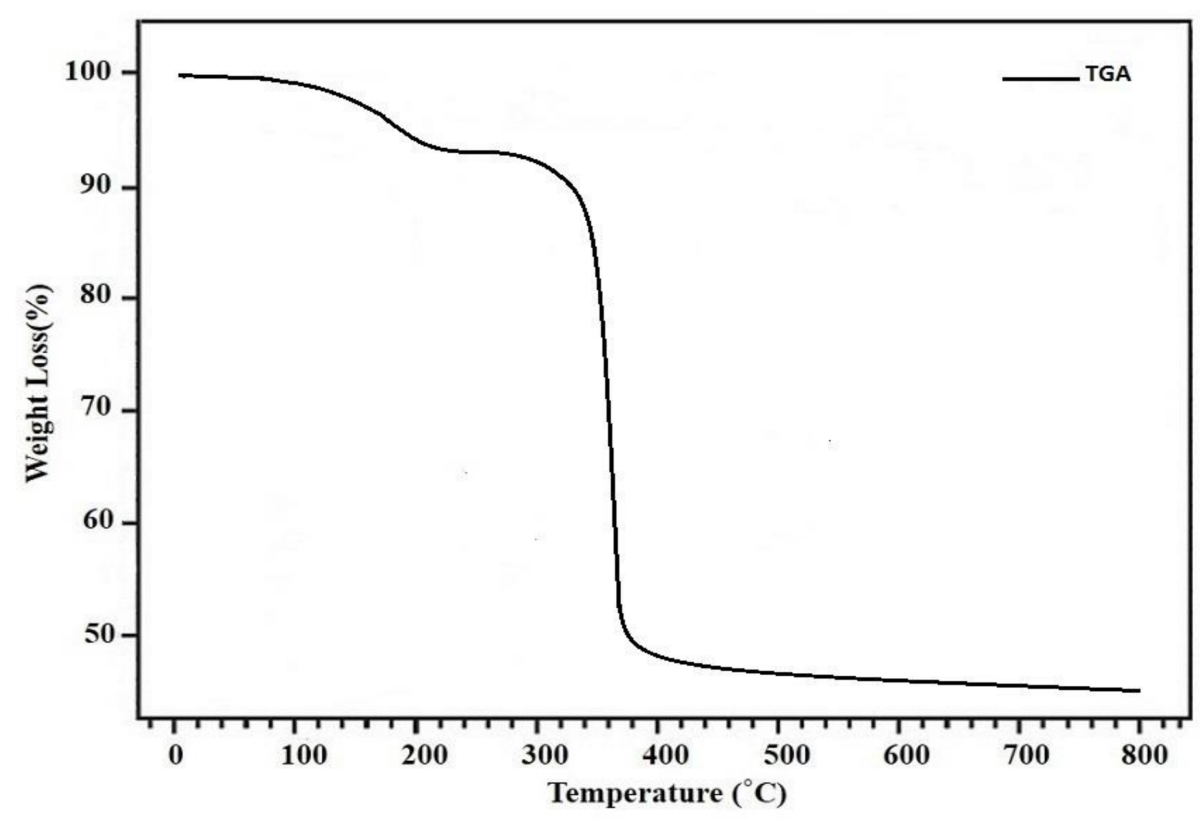

Figure 11. Thermal gravimetric (TG) thermogram of $\left[\mathrm{Cd}(\mathrm{L})\left(\mathrm{NO}_{2}\right)_{2}\right]_{\mathrm{n}}$. 


\section{Conclusions}

In the present study, a novel cadmium (II) coordination polymer $\left[\mathrm{Cd}(\mathrm{L})\left(\mathrm{NO}_{2}\right)_{2}\right]_{\mathrm{n}}$ nanostructure was prepared in an ultrasound-assisted manner and also compared by its crystal structure. The structural characterization of new coordination compounds was carried out by elemental analysis, IR spectroscopy, SEM, and single-crystal crystallography. The complex's structure creates a 2D coordination polymer in solid-state. It was determined that the coordination number of Cd (II) ions is 7 with five oxygen of nitrite anions and two nitrogen atoms from two Schiff base ligand. With several weak interactions, the comprehensive system displayed a three-dimensional structure. Thermolysis of coordination polymer 1 results in CdO nanoparticles.

Author Contributions: Y.H.: supervision, writing-original draft; B.M.: investigation, writingreview and editing; J.D.: writing-review and editing. All authors have read and agreed to the published version of the manuscript.

Funding: This research was funded by grant number 32/1374 of the Sayyed Jamaleddin Asadabadi University.

Data Availability Statement: Not applicable.

Acknowledgments: The authors would like to express their gratitude to University of Qom for supporting this research.

Conflicts of Interest: The authors declare no conflict of interest.

\section{Appendix A}

Crystallographic data for the structure reported in this paper have been deposited with the Cambridge Crystallographic Data Centre as supplementary publication CCDC-2045446 for $\left[\mathrm{Cd}(\mathrm{L})\left(\mathrm{NO}_{2}\right)_{2}\right]_{\mathrm{n}}(\mathbf{1})$. Copies of the data can be obtained by request from the CCDC, 12 Union Road, Cambridge CB2 1EZ, UK (Fax: +441223336033, eMail: deposit@ccdc.cam.ac.uk).

\section{References}

1. Emhoff, K.A.; Balaraman, L.; Salem, A.M.H.; Mudarmah, K.I.; Boyd, W.C. Coordination chemistry of organic nitric oxide derivatives. Coord. Chem. Rev. 2019, 396, 124-140. [CrossRef]

2. Liu, X.; Hamon, J.R. Recent developments in penta-, hexa- and heptadentate Schiff base ligands and their metal complexes. Coord. Chem. Rev. 2019, 389, 94-118. [CrossRef]

3. Mirtamizdoust, B. Sonochemical synthesis of nano lead(II) metal-organic coordination polymer; New precursor for the preparation of nano-materials. Ultrason Sonochem. 2017, 35, 263-269. [CrossRef]

4. Rasheed, T.; Hassan, A.A.; Bilal, M.; Hussain, T.; Rizwan, K. Metal-organic frameworks based adsorbents: A review from removal perspective of various environmental contaminants from wastewater. Chemosphere. 2020, 259, 127369. [CrossRef]

5. Engel, E.R.; Scott, J.L. Advances in the green chemistry of coordination polymer materials. Green Chem. 2020, 22, 3693-3715. [CrossRef]

6. Mishra, A.; Jo, J.H.; Kim, H.; Woo, S.; Chi, K.W. A Discrete Cobalt Complex Obtained from a 1D Coordination Polymer for Highly Selective Sensing of the Mercury (II) Ion. ChemPlusChem 2014, 79, 925-928. [CrossRef]

7. Guo, Y.; Hu, X.; Zhang, X.; $\mathrm{Pu}$, X.; Wang, Y. The synthesis of a $\mathrm{Cu}$ (II) Schiff base complex using a bidentate $\mathrm{N}_{2} \mathrm{O}_{2}$ donor ligand: Crystal structure, photophysical properties, and antibacterial activities. RSC Adv. 2019, 9, 41737. [CrossRef]

8. Chen, S.; Liu, X.; Ge, X.; Wang, Q.; Xie, Y.; Hao, Y.; Zhang, Y.; Zhang, L.; Shang, W.; Liu, Z. Lysosome-targeted iridium(III) compounds with pyridine-triphenylamine Schiff base ligands: Syntheses, antitumor applications and mechanisms. Inorg. Chem. Front. 2020, 7, 91-100. [CrossRef]

9. Che, C.M.; Huang, J.S. Metal complexes of chiral binaphthyl Schiff-base ligands and their application in stereoselective organic transformations. Coord. Chem. Rev. 2003, 242, 97-113. [CrossRef]

10. Himed, Y.; Komatsuzaki, N.O.; Sugihara, H.; Arakawa, H.; Kasuga, K. Transfer hydrogenation of a variety of ketones catalyzed by rhodium complexes in aqueous solution and their application to asymmetric reduction using chiral Schiff base ligands. J. Mol. Catal A Chem. 2003, 195, 95-100. [CrossRef]

11. Miroslaw, B. Homo-and Hetero-Oligonuclear Complexes of Platinum Group Metals (PGM) Coordinated by Imine Schiff Base Ligands. Int. J. Mol. Sci. 2020, 21, 3493. [CrossRef]

12. Vigato, P.A.; Tamburini, S. The challenge of cyclic and acyclic Schiff bases and related derivatives. Coord. Chem. Rev. 2004, 248, 1717-2128. [CrossRef] 
13. Leovac, V.M.; Jevtovic, V.S.; Jovanovic, L.S.; Bogdanovic, G.A. Metal complexes with Schiff-base ligands-Pyridoxal and semicarbazide-based derivatives. J. Serb. Chem. Soc. 2005, 70, 393-422. [CrossRef]

14. Wilkinson, S.M.; Sheedy, T.M.; New, E.J. Synthesis and Characterization of Metal Complexes with Schiff Base Ligands. J. Chem. Educ. 2016, 93, 351-354. [CrossRef]

15. Masoomi, M.Y.; Morsali, A. Applications of metal-organic coordination polymers as precursors for preparation of nano-materials. Coord. Chem. Rev. 2012, 256, 2921-2943. [CrossRef]

16. Malik, M.A.; O’Brien, P. Organometallic and Metallo-Organic Precursors for Nanoparticles. In Precursor Chemistry of Advanced Materials; Springer: Berlin/Heidelberg, Germany, 2005; p. 173.

17. Leong, W.L.; Vittal, J.J. One-Dimensional Coordination Polymers: Complexity and Diversity in Structures, Properties, and Applications. Chem. Rev. 2010, 111, 688-764. [CrossRef]

18. Vittal, J.J.; Ng, M.T. Chemistry of Metal Thio- and Selenocarboxylates: Precursors for Metal Sulfide/Selenide Materials, Thin Films, and Nanocrystals. Acc. Chem. Res. 2006, 39, 869-877. [CrossRef] [PubMed]

19. Das, K.; Datta, A.; Massera, C.; Sinha, C. Structural diversity, topology and luminescent properties of a two-dimensional Cd(II) coordination polymer incorporating 4,4'-dipyridyl and 4,4'-sulfonyldibenzoic. J. Mol. Struct. 2019, 1179, 618-622. [CrossRef]

20. Yadav, C.L.; Anamika; Rajput, G.; Kumar, K.; Drew, M.G.B.; Singh, N. Effect of Substituents on the Crystal Structures, Optical Properties, and Catalytic Activity of Homoleptic Zn(II) and Cd(II) $\beta$-oxodithioester Complexes. Inorg. Chem. 2020, 59, 11417-11431. [CrossRef] [PubMed]

21. Dutta, B.; Jana, R.; Sinha, C.; Ray, P.P.; Mir, M.H. Synthesis of Cd(II) based 1D coordination polymer by in situ ligand generation and fabrication of photosensitive electronic device. Inorg. Chem. Front. 2018, 5, 1998-2005. [CrossRef]

22. Mirtamizdoust, B.; Hanifehpour, Y.; Behzadfar, E.; Roodsari, M.S.; Jung, J.H.; Joo, S.W. A novel nano-structured three-dimensional supramolecular metal-organic framework for cadmium (II): A new precursor for producing nano cadmium oxide. J. Mol. Struct. 2020, 1201, 127191. [CrossRef]

23. Hanifehpour, Y.; Morsali, A.; Mirtamizdoust, B.; Joo, S.W. Sonochemical synthesis of tri-nuclear lead(II)-azido nano rods coordination polymer with 3,4,7,8-tetramethyl-1,10-phenanthroline (tmph): Crystal structure determination and preparation of nano lead(II) oxide. J. Mol. Struct. 2015, 1079, 67-73. [CrossRef]

24. Hanifehpour, Y.; Mirtamizdoust, B.; Hatami, M.; Khomami, B.; Joo, S.W. Synthesis and structural characterization of new bismuth (III) nano coordination polymer: A precursor to produce pure phase nano-sized bismuth (III) oxide. J. Mol. Struct. 2015, 1091, 43-48. [CrossRef]

25. Hanifehpour, Y.; Morsali, A.; Soltani, B.; Mirtamizdoust, B.; Joo, S.W. Ultrasound-assisted fabrication of a novel nickel(II)-bispyrazolyl borate twonuclear discrete nano-structured coordination compound. Ultrason Sonochem. 2017, 34, 519-524. [CrossRef] [PubMed]

26. Hammud, H.H.; Kortz, U.; Bhattacharya, S.; Demirdjian, S.; Hariri, E.; Isber, S.; Choi, E.S.; Mirtamizdoust, B.; Mroueh, M.; Daher, C.F. Structure, DFT studies, Magnetism and Biological activity of Bis[( $\mu$ 2-azido)-chloro-(1,10-phenanthroline)-copper(II)] complex. Inorganica Chim. Acta. 2020, 506, 119533. [CrossRef]

27. Kravtsov, V.C.; Lozovan, V.; Siminel, N.; Coropceanu, E.B.; Kulikova, O.V.; Costriucova, N.V.; Fonari, M.S. Fonari, From 1D to 2D $\mathrm{Cd}(\mathrm{II})$ and $\mathrm{Zn}$ (II) coordination networks by replacing monocarboxylate with dicarboxylates in partnership with azine ligands: Synthesis, crystal structures, inclusion, and emission properties. Polyhedron 2020, 180, 114411. [CrossRef]

28. Mercury 2.4, Copyright Cambridge Crystallographic Data Centre: 12 Union Road. Cambridge, UK; pp. $2001-2010$.

29. Oxford Diffraction. CrysAlis RED and CrysAlis CCD software (Ver. 1.171.32.5); Oxford Diffraction Ltd.: Abingdon, Oxfordshire, UK, 2010.

30. Pal, A.; Chand, S.; Elahi, S.M.; Das, M.C. A microporous MOF with a polar pore surface exhibiting excellent selective adsorption of $\mathrm{CO}_{2}$ from $\mathrm{CO}_{2}-\mathrm{N}_{2}$ and $\mathrm{CO}_{2}-\mathrm{CH}_{4}$ gas mixtures with high $\mathrm{CO}_{2}$ loading. Dalton Trans. 2017, 46, 15280-15286. [CrossRef]

31. Dong, Y.B.; Smith, M.D.; Loye, H.C.Z. New Inorganic/Organic Coordination Polymers Generated from Bidentate Schiff-Base Ligands. Inorg. Chem. 2000, 39, 4927-4935. [CrossRef]

32. Harrowfield, J.M.; Miyamae, H.; Skelton, B.W.; Soudi, A.A.; White, A.H. Lewis-Base Adducts of Lead (II) Compounds. XX. Synthesis and Structure of the 1:1 Adduct of Pyridine With Lead (II) Thiocyanate. Aust. J. Chem. 1996, 49, 1165-1169. [CrossRef]

33. Patterson, A.L. The Scherrer formula for X-ray particle size determination. Phys. Rev. 1939, 56, 978. [CrossRef]

34. Gao, E.Q.; Cheng, A.L.; Xu, Y.X.; Yan, C.H.; He, M.Y. New Inorganic-Organic Hybrid Supramolecular Architectures Generated from 2, 5-Bis (3-pyridyl)-3, 4-diaza-2, 4-hexadiene. Cryst. Growth Des. 2005, 5, 1005-1011. [CrossRef]

35. Lee, G.H.; Wang, H.T. Synthesis and Crystal Structure of a Three-Dimensional Nickel (II) Coordination Polymer with 1, 4-Bis (3-pyridyl)-2, 3-diazo-1, 3-butadiene as a Ligand. Anal. Sci. X-ray Struct. Anal. Online 2007, 23, x1-x2. [CrossRef]

36. Soltanzadeh, N.; Morsali, A. Metal-organic supramolecular assemblies generated from bismuth (III) bromide and polyimine ligands. Polyhedron 2009, 28, 703-710. [CrossRef]

37. Khanpour, M.; Morsali, A. Solid state crystal-to-crystal transformation from a monomeric structure to 1-D coordination polymers on anion exchange. CrystEngComm 2009, 11, 2585-2587. [CrossRef]

38. Mahmoudi, G.; Morsali, A. Three new HgII metal-organic polymers generated from 1, 4-bis (n-pyridyl)-3, 4-diaza-2, 4-hexadiene ligands. Inorg. Chim. Acta 2009, 362, 3238-3246. [CrossRef]

39. Velusamy, P.; Ramesh Babu, R.; Ramamurthi, K.; Elangovan, E.; Viegas, J.; Dahlem, M.S.; Arivanandhan, M. Characterization of spray pyrolytically deposited high mobility praseodymium doped CdO thin films. Ceram. Int. 2016, 42, 12675-12685. [CrossRef] 